\title{
Performance of HBsAg point-of-care tests for detection of diagnostic escape-variants in clinical samples
}

Cédric Hirzel MD ${ }^{1}$, Stefan Pfister PharmD ${ }^{2}$, Meri Gorgievski-Hrisoho ${ }^{2}$, Gilles Wandeler MD ${ }^{1}$, Samuel Zuercher MD ${ }^{2}$

1 Department of Infectious Diseases, Bern University Hospital and University of Bern, Switzerland

2 Institute for Infectious Diseases, University of Bern, Bern, Switzerland

Word count abstract: 156

Word count article: 1244

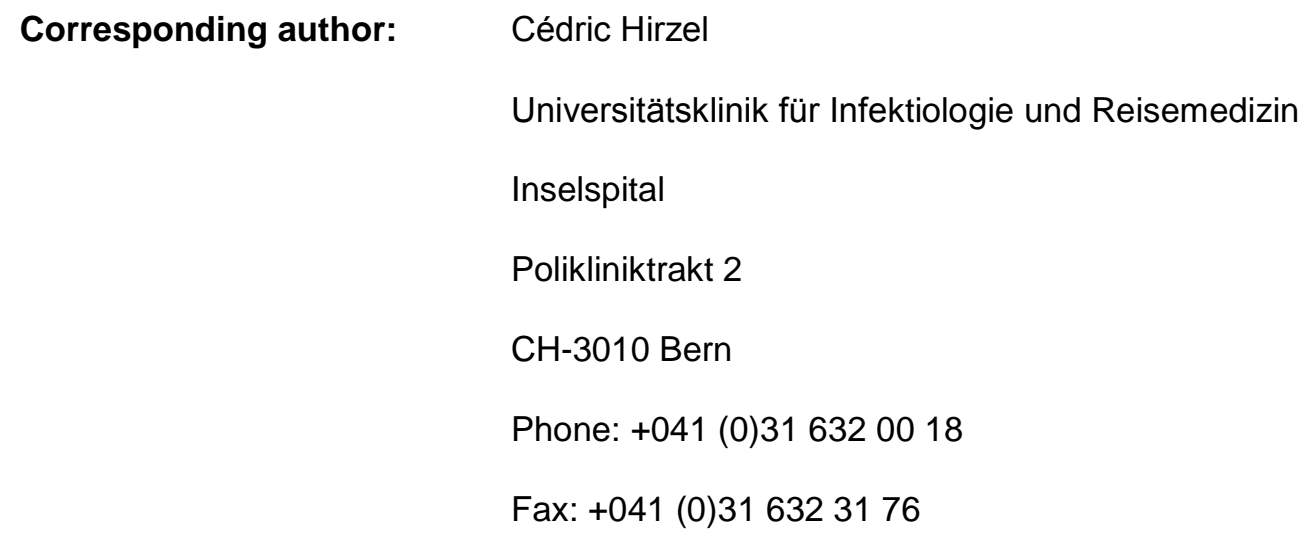




\section{Highlights}

- HBsAg point-of-care tests have slightly lower sensitivities than standard methods.

- We assessed test characteristics of point-of-care tests using HBsAg mutated viruses.

- The point-of-care tests accurately diagnosed mutated Hepatitis B viruses.

- HBsAg mutations do not affect the sensitivity of the evaluated tests. 


\section{Abstract}

2 Background: Hepatitis B viruses (HBV) harboring mutations in the a-determinant of the

3 Hepatitis B surface antigen (HBsAg) are associated with reduced reactivity of HBsAg assays.

4 Objectives: Evaluating the sensitivity and specificity of three HBsAg point-of-care tests for

5 the detection of HBsAg of viruses harboring HBsAg mutations.

6 Study design: A selection of 50 clinical plasma samples containing HBV with HBsAg

7 mutations was used to evaluate the test characteristics of three HBsAg point-of-care tests

8 (Vikia ${ }^{\circledR}$, bioMérieux, Marcy-L`Étoile, France. Alere Determine HBsAg ${ }^{\mathrm{TM}}$, Iverness Biomedical

9 Innovations, Köln, Germany. Quick Profile ${ }^{\mathrm{TM}}$, LumiQuick Diagnostics, California, USA) and

10 compared to the ARCHITECT HBsAg Qualitative ${ }^{\circledR}$ assay (Abbott Laboratories, Sligo,

11 Ireland).

Results: The sensitivity of the point-of-care tests ranged from $98 \%$ to $100 \%$. The only falsenegative result occurred using the Quick Profile ${ }^{\mathrm{TM}}$ assay with a virus harboring a D144A

14 mutation.

Conclusions: The evaluated point-of-care tests revealed an excellent sensitivity in detecting HBV samples harboring HBsAg mutations.

\section{Keywords}




\section{Background}

24 The mainstay of Hepatitis B virus (HBV) infection diagnosis is the detection of the HBV surface antigen (HBsAg) [1]. In recent years an increasing number of HBsAg point-of-care (POC) tests have become available. POC tests, which use the principle of immunochromatography as well as enzyme immunoassays and chemiluminescence immunoassays, are based on the detection of the antigenic determinant ("a-determinant").

The a-determinant is located between amino acid position 99 and 160 of the HBsAg [2]. However, in a recent study from The Gambia, POC tests had a slightly lower sensitivity than the standard serological methods [3] . In diagnostic-escape variants, mutations in the adeterminant of the HBsAg are thought to influence the performance of HBsAg assays [2]. The diagnostic performance for mutant HBV has been shown to differ across commercial HBsAg assays, depending on which anti-HBsAg reagents are used [4]. Thus, the different capacity in detecting HBV diagnostic-escape variants between POC tests and standard HBsAg assays could be an explanation for the lower sensitivity of POC tests.

\section{Objectives}

38 To determine the performance of three commercial HBsAg POC tests (Vikia $囚$, bioMérieux, Marcy-L`Étoile, France. Alere Determine HBsAg ${ }^{\mathrm{TM}}$, Iverness Biomedical Innovations, Köln, Germany. Quick Profile ${ }^{\mathrm{TM}}$, LumiQuick Diagnostics, California, USA) in detecting HBV with HBsAg mutations of the antigenic determinant from clinical samples.

\section{Study Design}

We retrospectively screened all samples for HBsAg mutations that were sent to our reference laboratory for HBV genotyping between January 2010 and December 2013. All samples with any mutation of the HBsAg with the exception of serotype- (amino acid positions 122, 127, 140, 159, 160) or genotype- ( T118A, T125M, A128V) specific HBsAg polymorphisms $[5,6]$ were considered for this analysis. Twenty randomly selected HBsAg negative samples were used as negative controls. The HBV viral load was measured using 


\section{Results} USA).

COBAS AmpliPrep®/COBAS TaqMan® HBV test 2.0 (Roche Diagnostics, Indianapolis,

DNA was extracted using NucliSENS easyMAG® (bioMérieux, Paris, France). A fragment of the HBsAg was amplified in a primary PCR (pPCR) using the primers HBV_1F and HBV_4R [7]. If needed, a nested PCR ( $n P C R$ ) was performed using the primers HBV P1F_f and HBV S6_r [8]. All PCR products were purified using QIAquick® PCR Purification Kit (QIAGEN GMBH, Hilden, Germany). The purified amplicons were subjected to bidirectional Sanger sequencing using the primers HBV_1F [5] and HBV S6_r [8] for pPCR products and HBV P1F_f and HBV S6_r $[7,8]$ for nPCR products. Cycle sequencing was performed according to Platt et al [9]. After purification of the cycle sequencing products by the QIAGEN DyeEx® 2.0 Spin Kit (QIAGEN GMBH, Hilden, Germany) The electropherograms were acquired on a Applied Biosystems ${ }^{\circledR} 3130$ genetic analyzer (Life Technologies Europe BV, Nieuwerkerk, Netherlands) and then processed using SeqMan® (DNASTAR Inc., Madison, WI, USA). For in silico sequence analysis and detection of HBsAg mutations the open access interpretation tool geno2pheno was used [10].

The performance of three HBsAg POC tests (Vikia ${ }^{\circ}$, Alere Determine HBsAg ${ }^{\mathrm{TM}}$, Quick Profile $^{\mathrm{TM}}$ ) previously validated in a French cohort [11] was compared with that of the ARCHITECT HBsAg Qualitative ${ }^{\circledR}$ assay, which has an excellent sensitivity in detecting HBsAg mutants [12]. False-negative and borderline POC test results were repeated twice. The ARCHITECT HBsAg Quantitative ${ }^{\circledR}$ assay was additionally performed in samples with false-negative POC tests and in samples harboring the same mutations as the false-negative ones. This allowed determining if false-negative results were caused by lower HBsAg levels. All tests were performed according to the manufacturer`s instruction.

Of 153 samples sequenced between 2010 and 2013, 50 contained HBsAg mutations. Fortyone different single or combined mutations were detected (Table 1). With the exception of six 
samples containing the mutations T118S, T126A, T126N, H129L, Y134R or W196L, all mutant variants had been previously associated with reduced sensitivity for HBsAg detection [2], occurrence of occult HBV infection [13-15], reduced binding of anti-HBsAg antibodies [16] or reduced HBsAg secretion [17]. The median HBV viral load was $14937 \mathrm{IU} / \mathrm{ml}$ (IQR 1`139-329`750 IU/ml). Genotype D was the most prevalent $(52.0 \%, 13 / 50)$ followed by A $(26.0 \%, 13 / 50)$, B (10.0\%, 5/50), C (6.0\%, 3/50), E (4.0\%, 2/50) and $F(2.0 \%, 1 / 50)$.

The sensitivity and specificity of the HBsAg POC tests were excellent (Table 2). The only false-negative test occurred using the Quick Profile ${ }^{\mathrm{TM}}$ assay with a HBV diagnostic escape variant harboring the single mutation D144A (HBV viral load $432 \mathrm{IU} / \mathrm{ml}$; quantitative HBsAg $140.4 \mathrm{IU} / \mathrm{ml})$. Of note, the Quick Profile ${ }^{\mathrm{TM}}$ assay produced a borderline positive result using another sample harboring the mutation F134A/D144A (HBV viral load $603 \mathrm{IU} / \mathrm{ml}$; quantitative HBsAg $14.8 \mathrm{IU} / \mathrm{ml}$ ) but was clearly positive for a sample with a D144A/G145A (HBV viral load 41`850`456 IU/ml, quantitative HBsAg $998.7 \mathrm{IU} / \mathrm{ml}$ ) and a Y100C/Y134H/D144A (HBV viral load $22815 \mathrm{IU} / \mathrm{ml}$, quantitative HBsAg $1146.5 \mathrm{IU} / \mathrm{ml}$ ) mutation. The electropherograms of the four samples containing a D144A mutation showed single peaks at the amino acid position 144. Therefore the correct identification of viruses harboring the D144A mutation could not be explained by the presence of non-mutated HBV sub-populations.

\section{Discussion}

This is the first study to assess the performance of HBsAg POC tests in diagnosing HBV harboring HBsAg mutations from clinical samples. We showed that the sensitivity and specificity of the assays were excellent. One false-negative and one borderline positive test occurred, both using the Quick Profile ${ }^{\mathrm{TM}}$ assay.

Bottero et al tested the performance of the identical HBsAg POC tests using whole blood samples in a large cohort in France [11]. They found high sensitivities (Vikia ${ }^{\circ}$ 96.5\%, Alere Determine HBsAg ${ }^{\text {TM }}$ 93.6\%, Quick Profile ${ }^{\mathrm{TM}}$ 90.5\%) and specificities (Vikia ${ }^{\circledR}$ 99.9\%, Alere Determine HBsAg ${ }^{\text {TM }} 100 \%$, Quick Profile ${ }^{\circledR}$ 99.7\%). Because of the low HBV viral loads in the samples with false-negative POC test results, they were not able to investigate whether 
103

104

105

106

107

108

109

110

111

112

113

114

115

116

false-negatives were caused by HBsAg mutations or by other factors. The sensitivity of POC tests was even higher in our study, despite analyzing HBV samples harboring HBsAg mutations. However, we did not have samples with low viral loads, as we only included those which were successfully sequenced and therefore the sensitivities of the POC test may be overestimated. We used plasma, which, according to the manufacturer's information, leads to a slightly higher sensitivity than whole blood with the Vikiaß assay. However, this is not true for the Alere Determine ${ }^{\mathrm{TM}}$ - and unknown for the Quick Profile ${ }^{\mathrm{TM}}$ assay.

In line with findings from Muhlbacher et al, we showed that a specific mutation did not always have the same effect on the result of the assay [18]. In our study the sample with a single D144A mutation was not detected by one of the tests, whereas for viruses harboring additional mutations, the result was either borderline positive or clearly positive. This phenomenon was not explained by lower quantities of HBsAg in the false-negative sample.

This was the first study to evaluate the sensitivity of HBsAg POC tests for diagnostic escape mutants using clinical samples with a wide variety of mutations and HBV genotypes. We recognize that in clinical settings, HBsAg POC tests are generally performed using whole blood and not serum or plasma. However, in light of recently published evidence, we did not expect the use of plasma to affect our results significantly [19].

In conclusion we demonstrated that the three HBsAg POC tests accurately diagnosed HBsAg diagnostic escape variants in plasma samples. Besides a potentially slightly reduced performance of the Quick Profile ${ }^{\mathrm{TM}}$ assay in detecting D144A mutants, our results indicate that HBsAg mutants do not relevantly affect the sensitivity of the evaluated POC tests.

\section{Acknowledgement}

GW was supported by an Ambizione-PROSPER fellowship from the Swiss National Science Foundation (PZO0P3_154730). 


\section{Conflict of Interest}

129 Funding: None

130 Competing interests: None

131 Ethics approval: Not required

132

133

134

135

136

137

138

139

140

141

142

143

144

145

146

147

148

149 
152 [1] Lok AS, McMahon BJ. Chronic hepatitis B: update 2009. Hepatology 2009;50:661-

153662.

154 [2] Alavian SM, Carman WF, Jazayeri SM. HBsAg variants: diagnostic-escape and 155 diagnostic dilemma. Journal of clinical virology : the official publication of the Pan American 156 Society for Clinical Virology 2013;57:201-208.

157 [3] Njai HF, Shimakawa Y, Sanneh B, Ferguson L, Ndow G, Mendy M, et al. Validation of 158 Rapid Point-of-Care (POC) Tests for Detection of Hepatitis B Surface Antigen in Field and 159 Laboratory Settings in the Gambia, Western Africa. Journal of clinical microbiology $160 \quad 2015 ; 53: 1156-1163$.

161 [4] Ly TD, Servant-Delmas A, Bagot S, Gonzalo S, Ferey MP, Ebel A, et al. Sensitivities 162 of four new commercial hepatitis B virus surface antigen (HBsAg) assays in detection of 163 HBsAg mutant forms. Journal of clinical microbiology 2006;44:2321-2326.

164 [5] Purdy MA, Talekar G, Swenson P, Araujo A, Fields H. A new algorithm for deduction 165 of hepatitis B surface antigen subtype determinants from the amino acid sequence. 166 Intervirology 2007;50:45-51.

167 [6] Tallo T, Tefanova V, Priimagi L, Schmidt J, Katargina O, Michailov M, et al. D2: major 168 subgenotype of hepatitis B virus in Russia and the Baltic region. The Journal of general 169 virology 2008;89:1829-1839.

170 [7] Mallory MA, Page SR, Hillyard DR. Development and validation of a hepatitis B virus 171 DNA sequencing assay for assessment of antiviral resistance, viral genotype and surface 172 antigen mutation status. Journal of virological methods 2011;177:31-37.

173 [8] Schildgen O, Sirma H, Funk A, Olotu C, Wend UC, Hartmann H, et al. Variant of 174 hepatitis B virus with primary resistance to adefovir. The New England journal of medicine $175 \quad 2006 ; 354: 1807-1812$. 
176 [9] Platt AR, Woodhall RW, George AL, Jr. Improved DNA sequencing quality and 177 efficiency using an optimized fast cycle sequencing protocol. BioTechniques 2007;43:58, 60, 17862.

179 [10] Beggel B, Neumann-Fraune M, Doring M, Lawyer G, Kaiser R, Verheyen J, et al. 180 Genotyping hepatitis B virus dual infections using population-based sequence data. The 181 Journal of general virology 2012;93:1899-1907.

182 [11] Bottero J, Boyd A, Gozlan J, Lemoine M, Carrat F, Collignon A, et al. Performance of 183 rapid tests for detection of $\mathrm{HBsAg}$ and anti-HBsAb in a large cohort, France. Journal of 184 hepatology 2013;58:473-478.

185 [12] Lou SC, Pearce SK, Lukaszewska TX, Taylor RE, Williams GT, Leary TP. An 186 improved Abbott ARCHITECT assay for the detection of hepatitis B virus surface antigen 187 (HBsAg). Journal of clinical virology : the official publication of the Pan American Society for 188 Clinical Virology 2011;51:59-63.

189 [13] Chamni N, Louisirirotchanakul S, Oota S, Sakuldamrongpanish T, Saldanha J, 190 Chongkolwatana V, et al. Genetic characterization and genotyping of hepatitis B virus (HBV) 191 isolates from donors with an occult HBV infection. Vox sanguinis 2014;107:324-332.

192 [14] Pei R, Grund S, Verheyen J, Esser S, Chen X, Lu M. Spontaneous reactivation of 193 hepatitis B virus replication in an HIV coinfected patient with isolated anti-Hepatitis B core 194 antibodies. Virology journal 2014;11:9.

195 [15] Motta JS, Mello FC, Lago BV, Perez RM, Gomes SA, Figueiredo FF. Occult hepatitis 196 B virus infection and lamivudine-resistant mutations in isolates from renal patients 197 undergoing hemodialysis. Journal of gastroenterology and hepatology 2010;25:101-106. 198 [16] Torresi J, Earnest-Silveira L, Deliyannis G, Edgtton K, Zhuang H, Locarnini SA, et al. 199 Reduced antigenicity of the hepatitis B virus HBsAg protein arising as a consequence of 200 sequence changes in the overlapping polymerase gene that are selected by lamivudine 201 therapy. Virology 2002;293:305-313. 
202 [17] Huang CH, Yuan Q, Chen PJ, Zhang YL, Chen CR, Zheng QB, et al. Influence of 203 mutations in hepatitis B virus surface protein on viral antigenicity and phenotype in occult 204 HBV strains from blood donors. Journal of hepatology 2012;57:720-729.

205 [18] Muhlbacher A, Weber B, Burgisser P, Eiras A, Cabrera J, Louisirirotchanakul S, et al. 206 Multicenter study of a new fully automated HBsAg screening assay with enhanced sensitivity 207 for the detection of HBV mutants. Medical microbiology and immunology 2008;197:55-64. 208 [19] Freeya Njai H, Shimakawa Y, Sanneh B, Ferguson L, Ndow G, Mendy M, et al. 209 Validation of rapid point-of-care (POC) tests for the detection of hepatitis B surface antigen 210 (HBsAg) in field and laboratory settings in The Gambia, West Africa. Journal of clinical 211 microbiology 2015. 


\section{Table 1}

HBsAg variants used for test evaluation

\begin{tabular}{|c|c|c|c|}
\hline HBsAg mutation (Genotype) & $\mathrm{n}$ & HBsAg mutation (Genotype) & $\mathrm{n}$ \\
\hline${\mathrm{Y} 100 \mathrm{C}^{\prime}(\mathrm{A} 1)}$ & 1 & G130N ${ }^{2} / T 131 N^{2}(D 3)$ & 1 \\
\hline 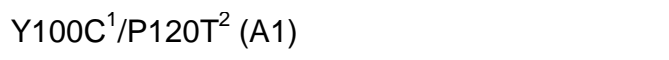 & 1 & $\left.\mathrm{~T} 131\right|^{2}(\mathrm{D} 4)$ & 1 \\
\hline $\mathrm{Y} 100 \mathrm{C}^{1} / \mathrm{T} 118 \mathrm{R} / \mathrm{P} 120 \mathrm{~A} / \mathrm{Y} 134 \mathrm{~L} / \mathrm{D} 144 \mathrm{E}^{2}$ (D1) & 1 & $\mathrm{~T} 131 \mathrm{~N}^{2}(\mathrm{~B} 2)$ & 1 \\
\hline $\mathrm{Y} 100 \mathrm{C}^{1} / \mathrm{Y} 134 \mathrm{H} / \mathrm{D} 144 \mathrm{~A}^{2}(\mathrm{D} 3)$ & 1 & $\mathrm{~T} 131 \mathrm{P}^{2}(\mathrm{D} 1)$ & 1 \\
\hline $\mathrm{T} 118 \mathrm{~K} / \mathrm{P} 120 \mathrm{~T}^{2}(\mathrm{C} 2)$ & 1 & $\mathrm{~T} 131 \mathrm{~N}^{2} / 1195 \mathrm{M}^{4}(\mathrm{~A} 1)$ & 1 \\
\hline T118S (D3) & 1 & $M 133 I^{2}(\mathrm{~A} 2)$ & 1 \\
\hline $\mathrm{P}_{120 \mathrm{~L}^{2}}$ (D3) & 1 & $\mathrm{M} 133 \mathrm{~L}^{2}$ (B2, B2) & 2 \\
\hline $\mathrm{P} 120 \mathrm{~S}^{2}$ (B4, D2, D3) & 3 & ${\mathrm{M} 133 \mathrm{~T}^{2}}_{(\mathrm{A} 1, \mathrm{D} 4)}$ & 2 \\
\hline $\mathrm{P} 120 \mathrm{~S}^{2} / \mathrm{G} 145 \mathrm{R}^{2}$ (D3) & 1 & 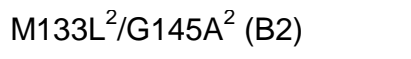 & 1 \\
\hline $\mathrm{C} 124 \mathrm{Y}^{2} / \mathrm{P} 135 \mathrm{~S}^{2}(\mathrm{D} 1)$ & 1 & 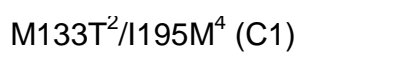 & 1 \\
\hline $\mathrm{T} 126 \mathrm{~A}(\mathrm{~A} 2)$ & 1 & Y134R (E) & 1 \\
\hline $\mathrm{T}_{126 \mathrm{I}^{1}}(\mathrm{C} 2)$ & 1 & $\mathrm{~F} 134 \mathrm{~A} / \mathrm{D} 144 \mathrm{~A}^{2}(\mathrm{D} 3)$ & 1 \\
\hline $\mathrm{T} 126 \mathrm{~N}(\mathrm{D} 3)$ & 1 & $\mathrm{P} 135 \mathrm{~S}^{2}$ (D4) & 1 \\
\hline T126N/Q129R ${ }^{5}$ (D1) & 1 & $\mathrm{C} 139 \mathrm{Y}^{2}(\mathrm{D} 1)$ & 1 \\
\hline $\mathrm{T} 126 \mathrm{~N} / \mathrm{Q} 129 \mathrm{R}^{5} / \mathrm{G} 145 \mathrm{~A}^{2}$ (D1) & 1 & $\mathrm{~S} 143 \mathrm{~L}^{2}(\mathrm{~F} 2)$ & 1 \\
\hline $\mathrm{H} 129 \mathrm{~L}(\mathrm{~A} 1)$ & 1 & $\mathrm{D} 144 \mathrm{~A}^{2}(\mathrm{D} 3)$ & 1 \\
\hline Q129A/G130R $\mathrm{R}^{2} / \mathrm{T} 131 \mathrm{~N}^{2} / \mathrm{M} 133 \mathrm{~T}^{2} / \mathrm{F} 134 \mathrm{~V}^{3}$ (D3) & 1 & $\mathrm{D} 144 \mathrm{~A}^{2} / \mathrm{G} 145 \mathrm{~A}^{2}(\mathrm{D} 3)$ & 1 \\
\hline $\mathrm{Q} 129 \mathrm{H}^{2} / \mathrm{G} 130 \mathrm{R}^{2} / \mathrm{T} 131 \mathrm{~N}^{2} / \mathrm{M} 33 \mathrm{~T}^{2} / \mathrm{F} 134 \mathrm{~V}^{3}$ (D3) & 1 & $\mathrm{I}_{195 \mathrm{M}^{4}}(\mathrm{~A} 1, \mathrm{~A} 2, \mathrm{D} 1, \mathrm{E})$ & 4 \\
\hline $\mathrm{G} 130 \mathrm{~N}^{2}(\mathrm{~A} 2)$ & 1 & W196L (A1, A2, D3) & 3 \\
\hline $\mathrm{G}_{130 R^{2}}(\mathrm{D} 2)$ & 1 & $\mathrm{~W} 196 \mathrm{~S}^{4}(\mathrm{~A} 2)$ & 1 \\
\hline $\mathrm{G} 130 \mathrm{R}^{2} / \mathrm{T} 131 \mathrm{~N}^{2}(\mathrm{D} 3)$ & 1 & & \\
\hline
\end{tabular}

1) Associated with occult HBV $[13,15]$

2) Associated with reduced sensitivity of HBsAg assays [2]

3) Associated with occult HBV in combination with additional mutations [14]

4) Associated with reduced binding to anti-HBs antibodies [16]

5) Asociated with reduced HBsAg secretion [17] 


\section{Table 2}

Test characteristics of HBsAg point-of-care tests compared to CMIA (ARCHITECT HBsAg Quantitative assay; Abbott Laboratories, Sligo, Ireland)

\begin{tabular}{lclll}
\hline & \multicolumn{2}{l}{ HBsAg serology CMIA } & Sensitivity & Specificity \\
\cline { 2 - 3 } & positive & negative & & \\
\hline VIKIA $®$ & $(\mathrm{n}=50)$ & $(\mathrm{n}=20)$ & $100 \%$ & $100 \%$ \\
positive & 50 & 0 & & \\
negative & 0 & 20 & & \\
\hline DETERMINE TM & $(\mathrm{n}=50)$ & $(\mathrm{n}=20)$ & $100 \%$ & $100 \%$ \\
positive & 50 & 0 & & \\
negative & 0 & 20 & & $100 \%$ \\
\hline QUICK PROFILE ${ }^{\text {TM }}$ & $(\mathrm{n}=50)$ & $(\mathrm{n}=20)$ & $98 \%$ & \\
positive & 49 & 0 & & \\
negative & 1 & 20 & & \\
\hline
\end{tabular}

